\title{
Incubatio: una práctica olvidada
}

\author{
Pedro Gargantilla-Madera, Berta M. Martín-Cabrejas, Emilio Pintor-Holguín
}

Todos sabemos que el período de incubación es el tiempo que tarda una enfermedad en manifestarse tras haberse contraído. Quizás lo que no sea tan conocido es que esta palabra deriva de una práctica médica griega, la incubatio, que se realizaba en la época prehipocrática [1] y que es ampliamente descrita en la comedia Pluto de Aristófanes.

El origen de la medicina (iaetria) en la civilización griega se relaciona directamente con la mitología, en donde no existe una clara línea divisoria entre lo humano y lo divino. Los griegos pensaban que eran los dioses quienes inspiraban el remedio curativo de sus dolencias [2]. Las principales divinidades sanadoras del panteón helénico fueron Apolo, inventor del arte de la curación, y su hijo Asclepio o Esculapio. En la Grecia clásica (s. III-V a.C.), los griegos dedicaron numerosos santuarios a Asclepio, de los cuales quedan vestigios en Cos, Pérgamo y Epidauro, epicentro de la sanación durante ese período $[1,3]$.

Hasta estos templos peregrinaban los enfermos, que eran recibidos por sacerdotes adscritos al templo (Asclepíades). A continuación ofrecían un sacrifico al dios (generalmente un gallo) y realizaban un complejo ritual (baños, masajes, unciones), preparándose para el descanso nocturno. Los pacientes dormían en el abaton, una zona del templo habilitada para ello, en las proximidades de la estatua del dios [1]. Descansaban con la confianza de que el dios los visitaría en la oscuridad y les pondría en estado para recobrar la salud a través del sueño sagrado (incubatio). Además de la incubatio, los Asclepíades realizaban una serie de actividades médicas propiamente dichas, entre las que se incluían intervenciones quirúrgicas, dietas especiales, el empleo de aguas medicinales, asistencia obligada al teatro y participación en determinadas ceremonias religiosas [3]. Era tradición que los pacientes atendidos y sanados ofreciesen exvo- tos consistentes en reproducciones en arcilla de los órganos tratados.

Las culebras de Esculapio (Zamenis longissimus) son unas serpientes de la familia Colubridae carentes de veneno y que estaban ligadas al cultos del dios; estos reptiles solían encontrarse en libertad en los aledaños del templo [3]. La relación entre la serpiente y Esculapio se debe a que este animal simbolizaba la renovación, puesto que muda de piel todos los años.

Gran parte de esta enseñanza aparece recogida en Pluto, la última comedia del escritor griego Aristófanes (448-385 a.C.), en la cual plantea el problema de la desigualdad de la distribución de las riquezas del mundo [4]. En la trama, Pluto, el dios de la riqueza, había sido cegado por Zeus y deambulaba por el mundo repartiendo riqueza de una forma arbitraria. En cierta ocasión se encontró con Crémilo, un agricultor pobre pero de enorme bondad, que lo condujo a la cueva de Asclepio para que le devolviera la vista [4]. El dios apareció en forma de serpiente y con la ayuda de un lienzo le limpió los párpados, devolviéndole la visión. A partir de ese momento, Pluto condenó a los perversos a la miseria y otorgó la riqueza a los honestos.

El culto a Asclepio alcanzó su cénit hacia el año 500 a.C. [3], momento en el que había más de 300 templos consagrados a esta divinidad en el mundo helénico; fue tal su importancia que los Asclepíades llegaron a formar una especie de corporación.

\section{Bibliografía}

1. Laín-Entralgo P. Historia de la medicina. Barcelona: Masson; 2006.

2. Castiglioni A. Encantamiento y magia. 2 ed. México DF: Fondo de Cultura Económica; 1991.

3. Gargantilla P. Manual de historia de la medicina. 4 ed. Málaga: Grupo Editorial 33; 2015.

4. Aristófanes. Comedias III. Barcelona: Gredos; 2013.
Servicio de Medicina Interna; Hospital de El Escorial (P. Gargantilla-Madera, E. Pintor-Holguín). Universidad Europea de Madrid (P. GargantillaMadera). Servicio de Ginecología y Obstetricia; Hospital Universitario Fundación Alcorcón (B.M. MartínCabrejas). Madrid, España.

Correspondencia:

Dr. Pedro Gargantilla Madera. Servicio de Medicina Interna. Hospital El Escorial. Ctra. M-600 de Guadarrama a San Lorenzo de El Escorial, km 6,255. E-28200 San Lorenzo de El Escorial (Madrid)

E-mail:

pgargantilla@yahoo.es

(c) $2016 \mathrm{FEM}$ 